\title{
Porphyrins Encapsulated into Pluronic F127 Micelles: Evaluating the Effect of the Central Metal and Substituents on the Photophysicochemical Properties in Water
}

\author{
Muthumuni Managa and Tebello Nyokong ${ }^{\circledR}$ \\ Dedicated to professor Aslan Yu. Tsivadze on the occasion of his Birthday \\ Centre for Nanotechnology Innovation, Department of Chemistry, Rhodes University, 6140 Grahamstown, South Africa \\ ${ }^{\circledR}$ Corresponding authorE-mail: t.nyokong@ru.ac.za
}

\begin{abstract}
Metal free 5-(4-carboxyphenyl)-10,15,20-tris(phenyl)porphyrin (1-H $)$ and its ClGa derivative (1-ClGa), as well as metal free 5-(4-(4-carboxyphenoxy)phenyl)-10,15,20-tris(phenyl)porphyrin (2-H ) and its ClGa (2-ClGa), Zn (2-Zn)

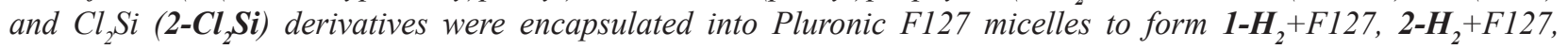

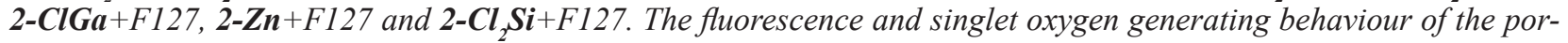
phyrins were also investigated. The Stern-Volmer constant $\left(K_{s v}\right)$ for $2-Z \mathbf{n}+F 127$ was the highest compared to other porphyrin derivatives.
\end{abstract}

Keywords: Carboxy porphyrins, singlet oxygen quantum yield, fluorescence quenching, Pluronic F127 micelles.

\section{Порфирины, инкапсулированные в мицеллы Pluronic F127: оценка влияния центрального металла и заместителей на фотофизико-химические свойства в воде}

\author{
М. Манага, Т. Ниоконг@ \\ Центр инноваций в области нанотехнологии, кафедра химии, Университет Родса, 6140 Грахамстаун, ЮАР \\ ${ }^{\circledR}$ E-mail: t.nyokong@ru.ac.za
}

5-(4-Карбоксифенил)-10,15,20-трис(фенил)порфирин (1-H $)$ и его ClGa комплекс (1-ClGa), а также 5-(4-(4-карбоксифенокси)фенил)-10,15,20-трис (фенил)порфирин (2-H2) и его ClGa (2-ClGa), Zn (2-Zn), Cl, Si

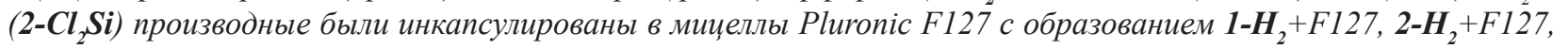
2-ClGa+F127, 2-Zn+F127 и 2-Cl $\mathbf{S i}+F 127$. Также были исследованы фллуресцениия и образование синглетного кислорода порфиринов. Константа Штерна-Фольмера $\left(K_{s v}\right)$ для 2-Zn+F127 была самой высокой по сравнению с другими производными порфиринов.

Ключевые слова: Карбоксипорфирины, квантовый выход синглетного кислорода, флуоресцентное тушение, мицеллы Pluronic F127. 


\section{Introduction}

Polymer micelles are fast becoming a powerful nanomedicine platform for cancer therapeutic applications because of their biocompatibility and relatively small size $(10-100 \mathrm{~nm})$ which help to prevent them from being recognized by proteins and macrophages therefore allowing for a greater circulation time. ${ }^{[1]}$ Polymer micelles also have the ability to solubilize water insoluble anticancer drugs such as porphyrins which are a subject of the current work. ${ }^{[2]}$

The polymeric micelles of interest in this work are the Pluronic triblock copolymers which are composed of poly(ethylene oxide) (PEO) and poly(propylene oxide) (PPO) with a PEO-PPO-PEO structure (Scheme 1). ${ }^{[3]}$ The PEO and PPO segments on the micelles act, respectively, as hydrophilic corona and hydrophobic core. ${ }^{[3]}$ Due to their biocompatibility and high drug loading ability, several Pluronics have been approved by Food and Drug Administration (FDA) for oral or intravenous administration because they are widely employed as solubilizers, emulsifiers or coating agents. ${ }^{[1,4-6]}$

Porphyrins have poor solubility ${ }^{[7]}$ and are also known to aggregate, ${ }^{[8]}$ which affects their photophysical behaviour. The driving forces behind the aggregation of porphyrins are the cooperative formation of hydrogen bonds, van-der-Waals forces and the hydrophobic effects. ${ }^{[9-11]}$ Pluronic micelles reduce self-aggregation and increase solubility of porphyrins in aqueous media. ${ }^{[9,12]}$

The porphyrins employed in this work are: metal free 5-(4-carboxyphenyl)-10,15,20-tris(phenyl)porphyrin (1-H $)$ and its $\mathrm{ClGa}$ derivative (complex 1-ClGa) as well as metal free 5-(4-(4-carboxyphenoxy)phenyl)-10,15,20-tris(phenyl) porphyrin $\left(\mathbf{2}-\mathbf{H}_{2}\right)$ and its $\mathrm{ClGa}, \mathrm{Zn}$ and $\mathrm{Cl}_{2} \mathrm{Si}$ derivatives (2-ClGa, 2-Zn, and $\mathbf{2}-\mathbf{C l}_{2} \mathbf{S i}$, respectively), Figure 1. The heavy $\mathrm{Ga}$ and $\mathrm{Zn}$ central metals as well as the chloride axial ligands for Ga and Si derivatives employed in this work will result in improved intersystem crossing to the triplet state due to the heavy atom effect, and subsequently increase singlet oxygen generation which is essential for PDT. This work reports for the first time on the encapsulation of complexes 1 and $\mathbf{2}$ onto Pluronic F127 which could expand and improve on areas of PDT applications. Complexes $\mathbf{2}$ have been linked to Pluronic-silica nanoparticles for PDT applications in organic media. ${ }^{[13]}$ In this work these complexes are embedded in Pluronic 127 micelles for the first time. Study of porphyrins in aqueous media is essential for applications in biological systems such as in PDT.

Porphyrins which are meso-phenyl substituted with carboxy functional groups have been reported as efficient second generation photosensitizers for PDT, ${ }^{[14]}$ hence complexes $\mathbf{1}$ and $\mathbf{2}$ are employed in this work.

\section{Experimental}

\section{Materials}

Pluronic F127 (MW $\sim 12.600 \mathrm{~g} / \mathrm{mol}$ ), potassium iodide, 9,10-anthracenediyl-bis(methylene)dimalonic acid (ADMA), metal free tetrakis(4-sulfonatophenyl)porphyrin ( $\mathrm{H}_{2} \mathrm{TSPP}$ ), and $\mathrm{Zn}$ tetraphenylporphyrin (ZnTPP) were purchased from Sigma-Aldrich. Dichloromethane (DCM) and dimethylformamide (DMF) were purchased from Merck. All other reagents and solvents were obtained from commercial suppliers and used as received. The syntheses of metal free 5-(4-carboxyphenyl)-10,15,20-tris(phenyl) porphyrin $\left(\mathbf{1}-\mathbf{H}_{2}\right)$ and its $\mathrm{ClGa}$ derivative (1-ClGa),$^{[15]}$ and metal free 5-(4-(4-carboxyphenoxy)phenyl)-10,15,20-tris(phenyl)porphyrin $\left(\mathbf{2}-\mathbf{H}_{2}\right)$ and its $\mathrm{ClGa}, \mathrm{Zn}$ and $\mathrm{Si}$ derivatives (2-ClGa, 2-Zn, $\left.\mathbf{2}-\mathbf{C l}_{2} \mathbf{S i}\right),{ }^{[13]}$ Figure 1, have been reported.

\section{Equipment}

Ground state electronic absorption spectra were recorded at room temperature using on a Shimadzu UV-2550 spectrophotometer and a $1 \mathrm{~cm}$ pathlength cuvette. Dynamic light scattering (DLS) experiments were done on a Malvern Zetasizer nanoseries, NanoZS90. Fluorescence emission spectra were recorded on a Varian Eclipse spectrofluorometer. Fluorescence lifetimes were measured using a time correlated single photon counting setup (TCSPC) (FluoTime 300, Picoquant $\mathrm{GmbH}$ ) with a diode laser (excitation source: LDH-P-485 with $10 \mathrm{MHz}$ repetition rate, 88 ps pulse width). Details have been provided before. ${ }^{[16]}$

Photo-irradiations for singlet oxygen studies in water (in the presence of micelles) were done using a General Electric projector lamp $(300 \mathrm{~W})$. A water filter was used to filter off infrared radiations. Light intensities were measured with a POWER MAX5100 (Molelectron detector incorporated) power meter. This means irradiation encompassed both the $Q$ and Soret bands. Light intensity was determined to be $9.43 \cdot 10^{18}$ photons $\mathrm{s}^{-1} \cdot \mathrm{cm}^{-2}$. Background studies were performed to determine if ADMA degrades in the absence of porphyrins. Irradiation of ADMA was done under the same irradiation intensity and time used for singlet oxygen studies.

\section{Fluorescence quantum yield}

Fluorescence quantum yields $\left(\Phi_{\mathrm{F}}\right)$ were determined by comparative methods, ${ }^{[17]}$ Equation (1), using the fluorescence quantum yield of ZnTPP in DMF as a standard $\left(\Phi_{\mathrm{F}}^{\text {Std }}\right)=0.033 .{ }^{[18]}$

$$
\Phi_{\mathrm{F}}=\Phi_{\mathrm{F}}^{\mathrm{Std}} \frac{\mathrm{F} \mathrm{A} \mathrm{A}^{\mathrm{Std}} \mathrm{n}^{2}}{\mathrm{~F}^{\mathrm{Std}} \mathrm{A}\left(\mathrm{n}^{\mathrm{Std}}\right)^{2}},
$$

where $\mathrm{F}$ and $\mathrm{F}^{\mathrm{Std}}$ are the areas under the fluorescence curves for sample and standard, respectively. A and $\mathrm{A}^{\mathrm{Std}}$ are the absorbances of the sample and reference at the excitation wavelength, respectively. $n$ and $n_{\text {Std }}$ are the refractive indices of the solvent used for the sample and standard, respectively. Absorbance at the excitation wavelength was $\sim 0.05$ in order to minimize inner filter effects. At least three independent experiments were performed for the quantum yield determinations. Both the sample and the standard were excited at the same relevant wavelength.

\section{Singlet oxygen quantum yield $\left(\Phi_{\Delta}\right)$}

Singlet oxygen quantum yield values in water were determined under ambient conditions using the chemical method with ADMA as a singlet oxygen quencher in water using Equation (2). ${ }^{[19]}$

$$
\Phi_{\Delta}=\Phi_{\Delta}^{\mathrm{Std}} \frac{\mathrm{W} \mathrm{I}_{\mathrm{abs}}^{\mathrm{Std}}}{\mathrm{W}^{\mathrm{Std}} \mathrm{I}_{\mathrm{abs}}}
$$

where $\Phi_{\Delta}^{\text {Std }}$ is the singlet oxygen quantum yield for the standard $\left(\mathrm{H}_{2} \mathrm{TSPP}\right)$ in water $(=0.51),{ }^{[20]} \mathrm{W}$ and $\mathrm{W}^{\text {Std }}$ are the ADMA photobleaching rates in the presence of porphyrin derivatives under investigation and the standard, respectively. $\mathrm{I}_{\text {abs }}$ and $\mathrm{I}_{\text {abs }}$ std are the rates of light absorption by the porphyrin derivative and standard, respectively. 
$\mathrm{I}_{\mathrm{abs}}$ is determined by Equation (3).

$$
\mathrm{I}_{\mathrm{abs}}=\frac{\alpha \mathrm{SI}}{\mathrm{N}_{\mathrm{A}}}
$$

where $\alpha$ is the fraction of light absorbed, $\mathrm{S}$ is the cell area irradiated, $N_{\mathrm{A}}$ is Avogadro's constant and $I$ the light intensity. The absorbances used for Equation (3) are those of the porphyrins embedded in micelles. The light intensity measured refers to the light reaching the spectrophotometer cells and it is expected that some of the light may be scattered since the system is heterogeneous. In addition, the wavelength employed covers a wide range, hence the $\Phi_{\Delta}$ values of the porphyrins in the micelles are estimates and used for comparison only.

\section{Incorporation of porphyrins into Pluronic F127}

The incorporation of all porphyrins (structures shown in Figure 1) into micelles was carried out using the solid dispersion method which has been described in literature. ${ }^{[21,22]}$ This method involves cosolubilization of copolymer with the porphyrin, which is then followed by rotative evaporation as follows: $\mathbf{1}-\mathbf{H}_{\mathbf{2}}$ $\left(7.22 \cdot 10^{-4} \mathrm{M}\right), \mathbf{1 - C l G a}\left(6.57 \cdot 10^{-4} \mathrm{M}\right), \mathbf{2}-\mathrm{H}_{2}\left(6.66 \cdot 10^{-4} \mathrm{M}\right), \mathbf{2}-\mathbf{C l G a}$ $\left(5.85 \cdot 10^{-4} \mathrm{M}\right), \mathbf{2}-\mathbf{Z n}\left(5.92 \cdot 10^{-4} \mathrm{M}\right)$ and $\mathbf{2 - C l}, \mathbf{S i}\left(6.15 \cdot 10^{-4} \mathrm{M}\right)$ were each mixed with Pluronic F127 $\left(20 \% \mathrm{w} / \mathrm{V}, 1.5 \cdot 10^{-2} \mathrm{M}\right)$ in $10 \mathrm{~mL}$ DCM. The mixtures were sonicated for $15 \mathrm{~min}$ at room temperature. The solvent was then removed using the rotary evaporator. The achieved solid products were left in a vacuum desiccator for $12 \mathrm{~h}$ and then hydrated and vigorously stirred (Dubnoff metabolic shaking) at $70{ }^{\circ} \mathrm{C}$ for $4 \mathrm{~h}$. The solutions were transferred onto test tubes and left for $24 \mathrm{~h}$ undisturbed for precipitation of porphyrins which were not bound onto the polymer which were then filtered and the required product was dried. The porphyrins when loaded into Pluronic F127 are represented as $\mathbf{1}-\mathbf{H}_{\mathbf{2}}+\mathrm{F} 127, \mathbf{1 - C l G a}+\mathrm{F} 127$, 2-H + F127, 2-ClGa+F127, 2-Zn+F127 and 2-Cl 2 Si +F127.

\section{Fluorescence quenching}

For these studies, stock solutions $\left(1.0 \cdot 10^{-6} \mathrm{M}\right)$ based on the Soret band absorption peak of the porphyrin with the micelles of $\mathbf{1 - H}+\mathrm{F} 127, \quad \mathbf{1 - C l G a}+\mathrm{F} 127, \quad \mathbf{2}-\mathbf{H}_{2}+\mathrm{F} 127, \quad \mathbf{2 - C l G a}+\mathrm{F} 127$,

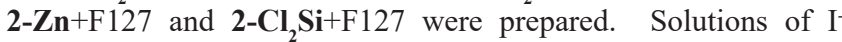
with different concentrations of $0 \mathrm{M}$ to $0.6 \mathrm{M}$ in water were also prepared. For the quenching experiments, $2.5 \mathrm{~mL}$ of the porphyrinmicelles and $500 \mu \mathrm{L}$ of different concentrations of $\mathrm{I}^{-}$were mixed (a total volume of $3 \mathrm{~mL}$ each time) and allowed to equilibrate for $5 \mathrm{~min}$ before fluorescence measurement were taken. Thus, the concentration of the porphyrin-micelles was kept constant while that of $\mathrm{I}^{-}$was varied. The actual concentration of $\mathrm{I}^{-}$in the mixture is employed for the calculations of the Stern-Volmer constants.

\section{Results and Discussion}

\section{Characterization of porphyrins when embedded in Pluronic F127}

The structures of the porphyrins employed are shown in Figure 1. The incorporation of all porphyrins into micelles was carried out using the solid dispersion method which has been described in literature ${ }^{[21,22]}$ as stated above. The porphyrins become water soluble after incorporation into Pluronic F127 micelles, hence all the studies are done in water in this work. No comparison can be made between porphyrins alone
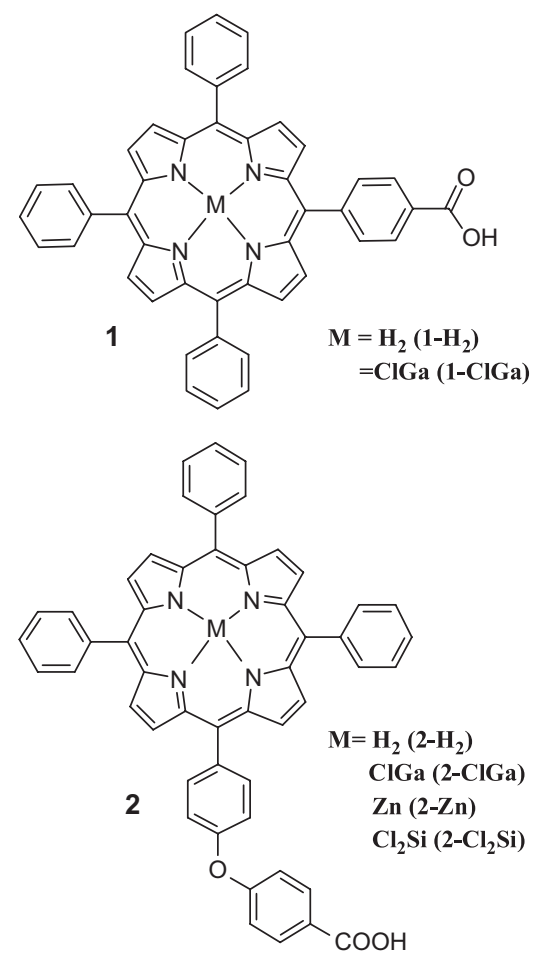

Figure 1. Structures of the porphyrins employed.

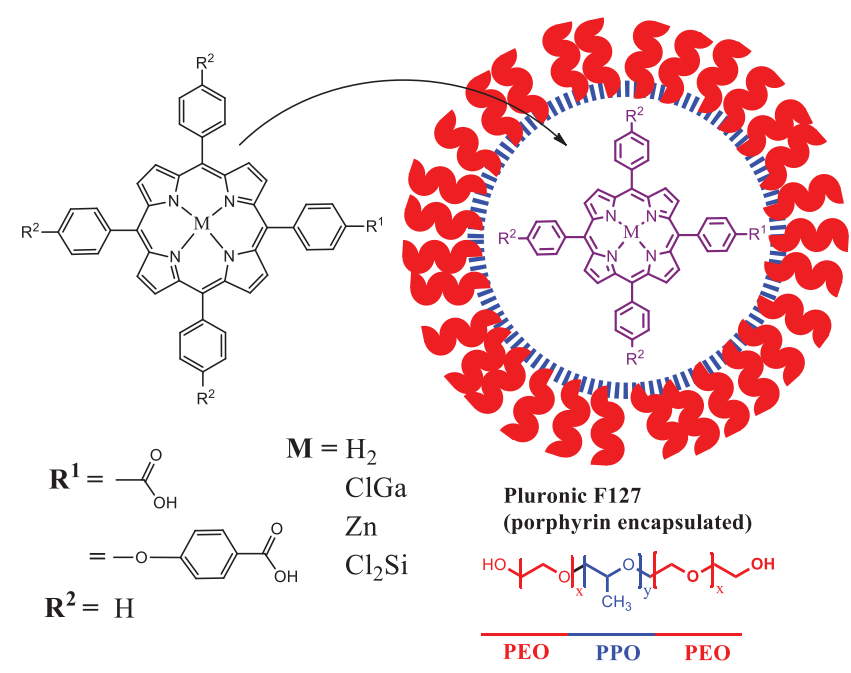

Scheme 1. Incorporation of the porphyrins into Pluronic F127.

dissolved in organic solvents and when they are embedded in micelles since different solvents are used. Also comparison with carboxylic acid porphyrins linked to Pluronic silica nanoparticles ${ }^{[13]}$ or linked to $\delta$-aminolevulinic acid ${ }^{[15]}$ is not possible since the reported work was done in organic media while this work is done on porphyrins is aqueous media.

\section{UV-Vis spectra}

The ground state electronic absorption spectra of porphyrins are characterized by an intense band called the Soret or B band at around $400 \mathrm{~nm}$. The Soret bands were observed at $418 \mathrm{~nm}, 423 \mathrm{~nm}$ for $\mathbf{1}-\mathbf{H}_{2}+\mathrm{F} 127$ and $\mathbf{1 - C l G a}+\mathrm{F} 127$, respectively. While the Soret bands of $\mathbf{2}-\mathbf{H}_{\mathbf{2}}+\mathrm{F} 127, \mathbf{2}-\mathbf{C l G a}+\mathrm{F} 127$, 

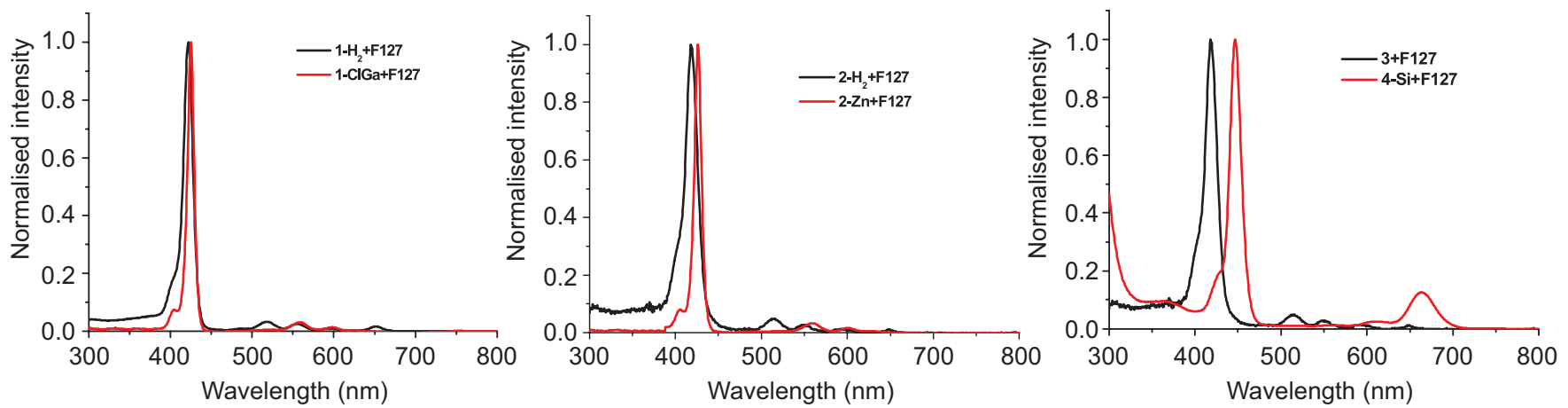

Figure 2. Normalised electronic absorption spectra of porphyrin when loaded in Pluronic F127 in water.

$\mathbf{2}-\mathbf{Z n}+\mathrm{F} 127$ and $\mathbf{2}-\mathbf{C l}_{\mathbf{2}} \mathbf{S i}+\mathrm{F} 127$ were observed at $419 \mathrm{~nm}$, $423 \mathrm{~nm}, 426 \mathrm{~nm}$ and $446 \mathrm{~nm}$, respectively (Table 1). The four $Q$-bands of the metal free porphyrins collapsed into two $Q$-bands for the metalated derivatives (Figure 2). There are red shifts in the Soret bands upon introduction of central metals for all porphyrins. Introduction of heavy metals results in degree of perturbation and electron delocalisation within the porphyrin macrocycle. ${ }^{[23]}$ In addition, red-shifts of Soret bands are often observed for distorted porphyrins. ${ }^{[24]}$ Comparing 2-H + F127, 2-ClGa+F127, 2-Zn+F127 and 2-Cl, $\mathbf{S i}+\mathrm{F} 127$; the latter $\left(\mathbf{2}-\mathbf{C l}_{2} \mathbf{S i}+\mathrm{F} 127\right)$ has a more red shifted Soret band. Broad and red shifted Soret band may also indicate $J$-aggregation of porphyrins. ${ }^{[25]}$ However, there is no clear broadening in Figure 2 for $\mathbf{2}-\mathbf{C l}_{2} \mathbf{S i}+\mathrm{F} 127$ even though there is more red-shifting for this conjugate compared to $\mathbf{2}-\mathbf{C l G a}+\mathrm{F} 127$ and $\mathbf{2}-\mathbf{Z n}+\mathrm{F} 127$. In order to check the effect of the substituent on the spectra, conjugates 1-ClGa+F127 and 2-ClGa +F127 containing the same central metal and different substituents were compared, but there was no shift in the Soret peak maxima, showing no substituent effect. The same applies when comparing $\mathbf{1}-\mathbf{H}_{2}+\mathrm{F} 127$ and $\mathbf{2}-\mathbf{H}_{2}+\mathrm{F} 127$, both metal free but containing different substituents.

After the determination of the $\varepsilon$ values of porphyrins in F127 aqueous solutions, the relationships between the photosensitizer incorporation capacity and the concentration were evaluated. The actual amounts of porphyrins embedded into micelles were determined from $\varepsilon$ values using the Beer-Lambert law and maximum absorbance of the $Q$ bands following reported methods. ${ }^{[26]}$ The values are that were determined to be $0.077,0.071,0.075,0.011$,

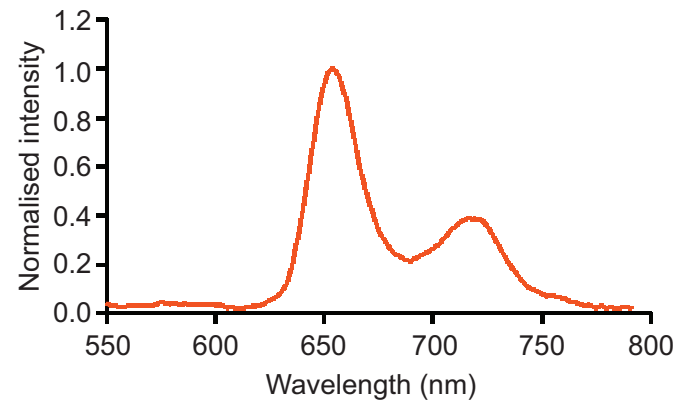

Figure 3. Fluorescence emission spectrum of $\mathbf{1}-\mathbf{H}_{2}+\mathrm{F} 127$ in water.

0.036 and $0.055 \mathrm{mg}$ of $\mathbf{1 - H}+\mathrm{F} 127, \mathbf{1 - C l G a}+\mathrm{F} 127, \mathbf{2}+\mathrm{F} 127$, 2-ClGa+F127, 2-Zn+F127 and 2-Cl_Si +F127, respectively, hence the highest loading is that of $\mathbf{1}-\mathbf{H}_{\mathbf{2}}+\mathrm{F} 127$, Table 1 .

Figure 3 shows the emission spectra of $\mathbf{1 - \mathbf { H } _ { 2 }}+\mathrm{F} 127$ as an example. The spectra are typical ${ }^{[27]}$ of porphyrins with two bands differing in intensity. Very weak emission signals were obtained for the rest of the conjugates due to the presence of heavy central metals and/or chlorine which will result in intersystem crossing to the triplet state hence quenching fluorescence.

\section{Dynamic light scattering (DLS)}

The micelle sizes were determined using dynamic light scattering (DLS). The size of Pluronic F127 has been previously been reported to be $14.6 \mathrm{~nm} \cdot{ }^{[21]}$ The sizes of the porphyrin containing micelles were determined

Table 1. The photophysical properties of porphyrins embedded in Pluronic F127 in water.

\begin{tabular}{|c|c|c|c|c|c|c|c|}
\hline Conjugates $^{\mathrm{a}}$ & $\begin{array}{l}\text { Amount of porphyrin } \\
\text { loaded (mg) }\end{array}$ & $\begin{array}{l}\lambda_{\mathrm{Abs}}{ }^{\mathrm{b}} \\
(\mathrm{nm})\end{array}$ & $\lambda_{\mathrm{Em}}^{\mathrm{b}}(\mathrm{nm})$ & $\Phi_{\mathrm{F}}$ & $\tau_{\mathrm{F}}(\mathrm{ns})$ & $\Phi_{\Delta}( \pm 0.01)$ & $K_{\mathrm{sv}}\left(\mathrm{M}^{-1}\right)$ \\
\hline $\mathbf{1}-\mathrm{H}_{2}+\mathbf{F} 127(15.65)$ & 0.077 & 418 & 655,719 & 0.10 & 4.63 & 0.29 & 0.26 \\
\hline 1-ClGa+F127 (30.91) & 0.071 & 423 & 615,654 & $<0.01$ & 3.20 & 0.31 & 1.79 \\
\hline $\mathbf{2}-\mathrm{H}_{2}+\mathbf{F} 127(16.35)$ & 0.075 & 419 & 657,720 & 0.11 & 4.06 & 0.32 & 0.35 \\
\hline 2-ClGa+F127 (33.57) & 0.011 & 423 & 615,657 & $<0.01$ & 3.11 & 0.37 & 2.18 \\
\hline 2-Zn+F127 (32.71) & 0.036 & 426 & 620,655 & $<0.01$ & 3.01 & 0.35 & 2.27 \\
\hline 2-Cl $2 \mathrm{Si}+\mathbf{F 1 2 7}(31.87)$ & 0.055 & 446 & 652,699 & $<0.01$ & 3.23 & 0.34 & 1.91 \\
\hline
\end{tabular}

${ }^{a}$ Values in brackets are the sizes determined by DLS in brackets. ${ }^{\mathrm{b}} \lambda_{\mathrm{Abs}}=$ absorption, $\lambda_{\mathrm{Em}}=$ emission. 

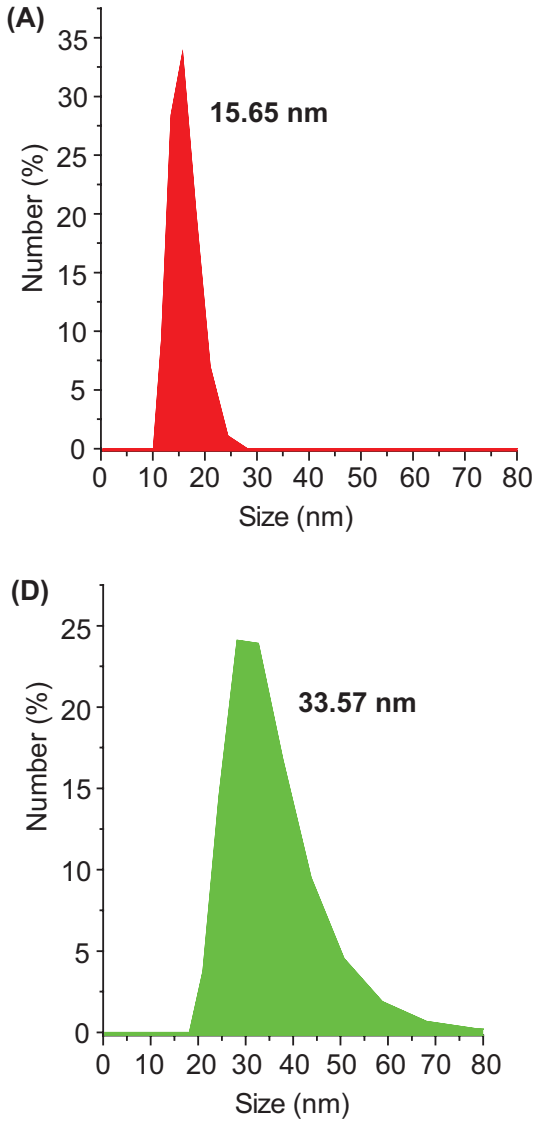

(B)

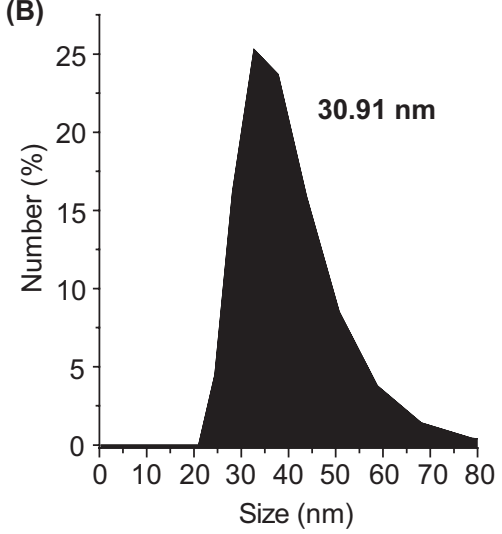

(E)

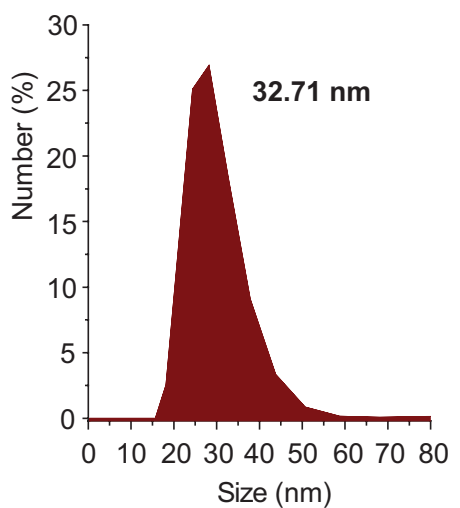

(C)

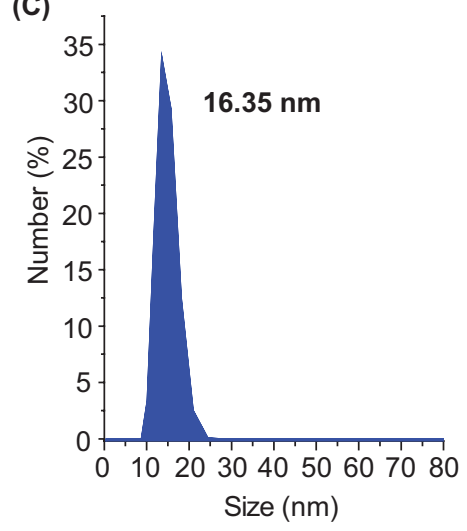

(F)

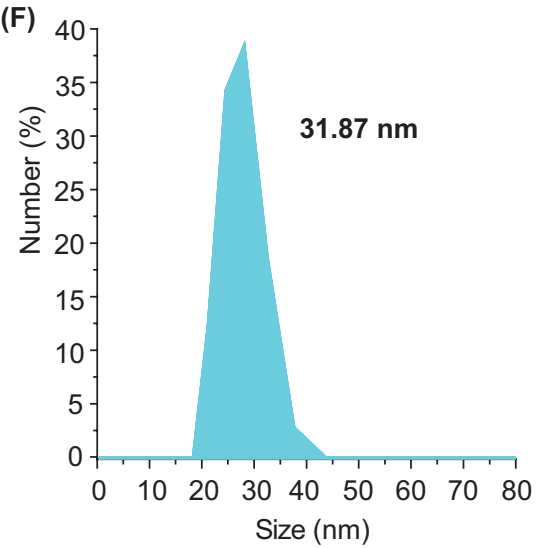

Figure 4. Dynamic light scattering of micelles containing porphyrins: (A) 1-H + F127, (B) 1-ClGa+F127, (C) 2-H + +F127, (D) 2-ClGa+F127, (E) 2-Zn+F127 and (F) 2-Cl2 Si.

to be $15.65 \mathrm{~nm}, 30.91 \mathrm{~nm}, 16.35 \mathrm{~nm}, 33.57 \mathrm{~nm}, 32.71 \mathrm{~nm}$ and $31.87 \mathrm{~nm}$ for $\mathbf{1 - H _ { 2 }}+\mathrm{F} 127, \mathbf{1 - C l G a}+\mathrm{F} 127, \mathbf{2}-\mathbf{H}_{\mathbf{2}}+\mathrm{F} 127$, 2-ClGa+F127, 2-Zn+F127 and 2-Cl_ Si+F127, respectively, Table 1. In all cases (Table 1 and Figure 4), metal free conjugates have smaller sizes as compared to the corresponding metalated derivatives. It has been reported that central metals within the cavity of the porphyrins change the hydrophobicity of the molecule. ${ }^{[28]}$ It was also found that the most hydrophobic drugs increased the sizes of the micellar core and corona, ${ }^{[29]}$ hence the increase in size of micelles containing metalated porphyrins compared to metal free ones could be a result of increased hydrophobicity of the former, while small differences in sizes for the micelles of metalated derivatives reflect small differences in hydrophobicity.

\section{Fluorescence quantum yields $\left(\Phi_{F}\right)$ and lifetimes $\left(\tau_{f}\right)$}

The florescence quantum yields $\left(\Phi_{\mathrm{F}}\right)$ were determined using a comparative method and exciting at $490 \mathrm{~nm}$. The $\Phi_{\mathrm{F}}$ of $\mathbf{1}-\mathbf{H}_{2}+\mathrm{F} 127$ and $\mathbf{2}-\mathbf{H}_{2}+\mathrm{F} 127$ were determined to be 0.10 and 0.11 , respectively, while those of 1-CIGa+F127, 2-ClGa+F127, $\mathbf{2 - Z n + F 1 2 7 ~ a n d ~} \mathbf{2 - C l} \mathbf{2} \mathbf{S i}+\mathrm{F} 127$ were all determined to be $<0.01$. The values in the presence of $\mathrm{ClGa}$ and $\mathrm{Zn}$ and $\mathrm{Cl}_{2} \mathrm{Si}$ are low due to the heavy atom effects of central metals and axial ligands, which results in intersystem crossing to the triplet state, reducing fluorescence.

The fluorescence life-time $\left(\tau_{\mathrm{f}}\right)$ values for $\mathbf{1}-\mathbf{H}_{\mathbf{2}}+\mathrm{F} 127$, $\mathbf{1 - C l G a}+\mathrm{F} 127, \quad \mathbf{2 - H _ { 2 }}+\mathrm{F} 127, \quad \mathbf{2 - C l G a}+\mathrm{F} 127, \quad \mathbf{2 - Z n}+\mathrm{F} 127$

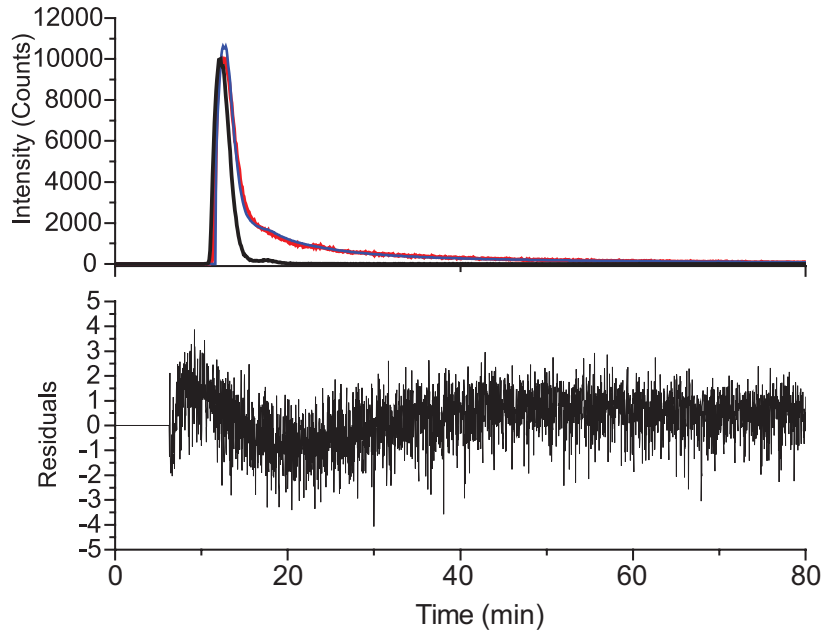

Figure 5. Fluorescence decay profile of $\mathbf{2 - Z n + F 1 2 7}$ as an example in water. Black line represents the instrument response function (IRF), blue line is the data and red line is the fitting.

and $\mathbf{2}-\mathbf{C l}_{2} \mathbf{S i}+\mathrm{F} 127$ were determined using a time correlated single photon count (TCSPC) method, following excitation at the emission maxima. A typical fluorescence decay profile for of 2-Zn+F127 as an example is shown in Figure 5. Monoexponential decay profiles were obtained for all porphyrin complexes. The $\tau_{\mathrm{f}}$ values follow the trend of $\Phi_{\mathrm{F}}$ since there is a decrease on metalation. 
Singlet oxygen quantum yield $\left(\Phi_{\Delta}\right)$

The metal free porphyrins generally have lower $\Phi_{\triangle}$ compared to metalated porphyrins, Table 1. ADMA was employed as a singlet oxygen quencher. As stated above, these values are estimates for comparison purposes only. Since the light used for singlet oxygen studies covered the range where ADMA absorbs, the effect of light on ADMA alone was investigated. There was no significant decrease in the absorbance of ADMA within the time scale used for singlet oxygen quantum yield studies. The values in the presence of $\mathrm{ClGa}, \mathrm{Zn}$ and $\mathrm{Cl}_{2} \mathrm{Si}$ are high due to the heavy atom effect of the central metals and axial $\mathrm{Cl}^{-}$ligands which results in intersystem crossing to the triplet state from which singlet oxygen is generated as previously mentioned. It has been reported in literature ${ }^{[30]}$ that an increase in $\Phi_{\triangle}$ values is expected when porphyrins are incorporated into Pluronic polymers, however the results previously reported are incomparable as they were carried out in DMF. ${ }^{[13,15]}$ According to literature, ${ }^{[8]}$ the PEO segment of the polymer may hinder collision of the porphyrin with surrounding molecules thus obstructing idle losses of the triplet state energy therefore increasing $\Phi_{\triangle}$. Comparing $\mathbf{1}-\mathbf{H}_{\mathbf{2}}+\mathrm{F} 127$ with $\mathbf{2}-\mathbf{H}_{\mathbf{2}}+\mathrm{F} 127$ both metal free, but containing different substituents shows that the latter gave larger $\Phi_{\triangle}$ value. Again, the same applies when comparing $\mathbf{1 - C l G a}+\mathrm{F} 127$ with $\mathbf{2 - C l G a}+\mathrm{F} 127$, both containing the same Ga central metal but different substituents, showing the effects of the bulkier phenoxy benzoic acid substituent. Comparing 2-CIGa+F127, 2-Zn+F127 and $\mathbf{2}-\mathbf{C l}_{2} \mathbf{S i}+\mathrm{F} 127$ shows that $\mathbf{2}-\mathbf{C l G a}+\mathrm{F} 127$ gave the largest $\Phi_{\triangle}$ value, showing the combined heavy atom effects of $\mathrm{Ga}$ and the $\mathrm{Cl}^{-}$axial ligand, though the effect is not too large. The higher loading for $\mathbf{1}-\mathbf{H}_{2}+\mathrm{F} 127$ could have also resulted in aggregation, hence the lowest $\Phi_{\Delta}$ value.

\section{Determination of Stern-Volmer constants}

The relative locations of porphyrins in Pluronic F127 micellar system were carried out by fluorescence quenching. $\mathrm{I}^{-}$was employed as a quencher. Stern-Volmer constants $\left(K_{\mathrm{sv}}\right)$ were calculated using Equation (4):

$$
\frac{\mathrm{F}_{0}}{\mathrm{~F}}=1+\mathrm{K}_{\mathrm{SV}}[\mathrm{Q}]
$$

where $\mathrm{F}_{0}$ and $\mathrm{F}$ are the fluorescence intensities in the absence and presence of the quencher, respectively, [Q] is the concentration of the quencher.

Figure 6A-B shows the fluorescence quenching spectra from which Stern-Volmer plots were derived. The SternVolmer plots (inserts (a)) showed nonlinear relationships. These types of plots can occur in the case of purely collisional quenching but with some of the fluorophores being less accessible than others. ${ }^{[31,32]}$ Inserts (a) in Figure 6 A-B are a characteristic feature of two fluorophore populations. Some porphyrins are buried in the polymer interior and are relatively inaccessible to iodide while the others are on the polymer surface and are more accessible. ${ }^{[31]}$

The deviation from linearity in the Stern-Volmer plots is accommodated by treating the data using a modified SternVolmer equation by Sam Lehrer Eq. (5) which takes into account situations where two populations of fluorophores exist, with one being accessible to quencher and the other being buried and not accessible. ${ }^{[33]}$

$$
\frac{\mathrm{F}_{0}}{\Delta \mathrm{F}}=\frac{1}{\left([\mathrm{Q}] \mathrm{f}_{\mathrm{a}} \mathrm{K}_{\mathrm{SV}}\right)}+\frac{1}{\mathrm{f}_{\mathrm{a}}},
$$

where $\mathrm{F}_{0}$ is the fluorescence intensity in the absence of quencher, $\Delta \mathrm{F}$ is the observed decrease in the fluorescence and $K_{\mathrm{sv}}$ is the Stern-Volmer quenching constant of the accessible fluorophore. $f_{\mathrm{a}}$ is the fluorescence of the fluorophore which is accessible to the quenchers (Q). Plots of $\mathrm{F}_{0} / \Delta \mathrm{F}$ versus $1 /[\mathrm{Q}]$ with an $\mathrm{Y}$-axis intercept of $1 / \mathrm{f}_{\mathrm{a}}$ are shown in Figure 6 A-B (inserts (b)).

A low $K_{\mathrm{sv}}$ value indicates that dyes are located in the micelle core, resulting in less encounter between incorporated photosensitizer and iodine. ${ }^{[33,34]}$ The $K_{\mathrm{sv}}$ values obtained for $\mathbf{1}-\mathbf{H}_{2}+\mathrm{F} 127$ was $0.26 \mathrm{M}^{-1}$ and was $1.79 \mathrm{M}^{-1}$ for 1-ClGa+F127. The $K_{\text {sv }}$ 2+F127, 2-ClGa+F127, 2-Zn+F127 and $\mathbf{2}-\mathbf{C l}_{2} \mathbf{S i}+\mathrm{F} 127$ were determined to be $0.35,2.18$, 2.27 and $1.91 \mathrm{M}^{-1}$. Thus, $\mathbf{2 - Z n}+\mathrm{F} 127$ is located more on
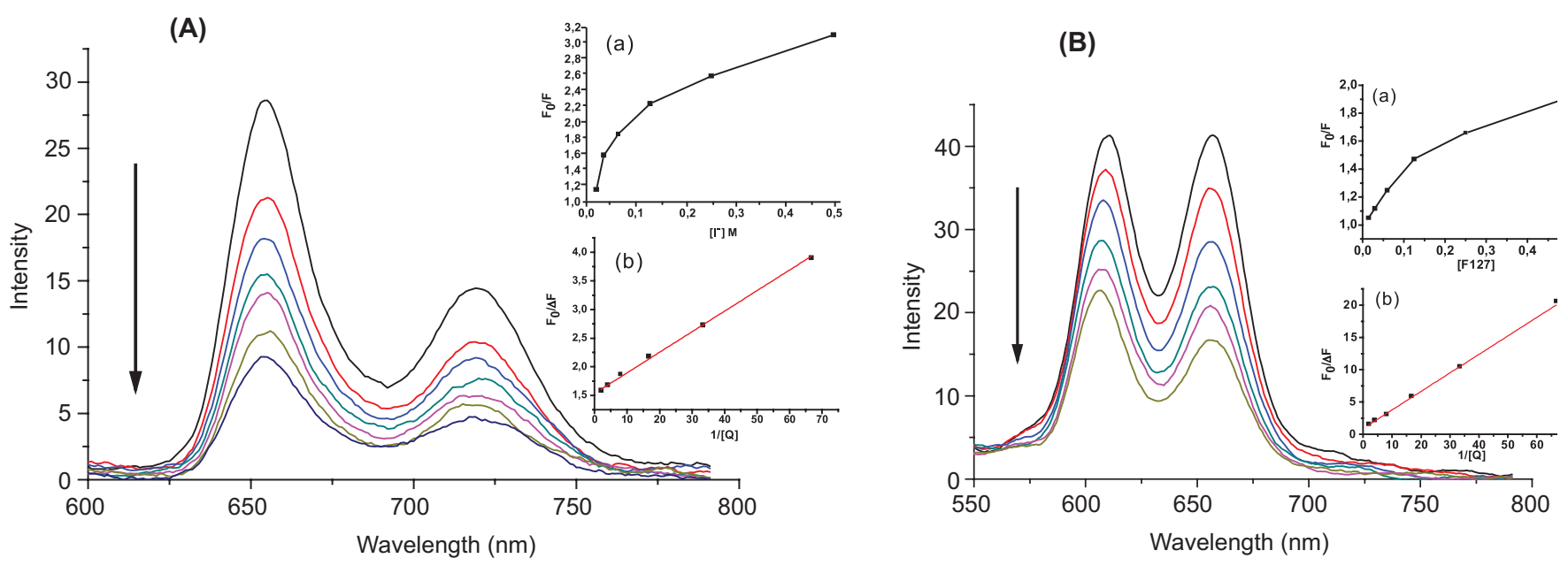

Figure 6. Fluorescence emission spectra for (A) $2-\mathbf{H}_{2}+\mathrm{F} 127$ and (B) $2-\mathbf{Z n}+\mathrm{F} 127$ (as examples) in the presence of $0 \mathrm{M}$ to $0.10 \mathrm{M}$ of KI. Excitation wavelength=490 nm. Inserts: (a) Stern-Volmer plot using Equation 4 and (b) modified Stern-Volmer plot using Equation 5. 
the hydrophilic outer area (and can interact with the quencher more) than the corresponding $\mathbf{2}-\mathbf{H}_{2}+\mathrm{F} 127$, 2-ClGa+F127, and $\mathbf{2}-\mathrm{Cl}_{2} \mathbf{S i}+\mathrm{F} 127$ since the former has a larger $K_{\mathrm{sv}}$ value. As stated above, metals in the centre of porphyrins changes the hydrophobicity of the molecule therefore resulting in the different locations for the porphyrins. Metal free derivatives $\mathbf{1}-\mathbf{H}_{\mathbf{2}}+\mathrm{F} 127$ and $\mathbf{2}-\mathbf{H}_{\mathbf{2}}+\mathrm{F} 127$ are located more in the hydrophobic inner core since they have the lower $K_{\mathrm{sv}}$ values compared to the corresponding metalated derivatives.

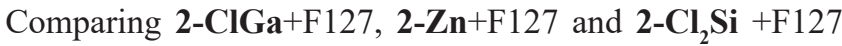
differing only in the central metal, the $\mathrm{Cl}_{2} \mathrm{Si}$ derivative is located more in the hydrophobic inner core (smaller $K_{\mathrm{sv}}$ value) probably due to the smaller size, while the largest $\mathrm{Zn}$ derivative is located more on the outer hydrophilic core (larger $K_{\text {sv }}$ value).

\section{Conclusions}

Metal free 5-(4-carboxyphenyl)-10,15,20-tris(phenyl) porphyrin) and its $\mathrm{ClGa}$ derivative as well as metal free 5-(4-(4-carboxyphenoxy)phenyl)-10,15,20-tris(phenyl) porphyrin and its $\mathrm{ClGa}, \mathrm{Zn}$ and $\mathrm{Cl}_{2} \mathrm{Si}$ derivatives were successfully encapsulated into Pluronic F127 micelles and upon encapsulation the porphyrins became water soluble which is ideal for biological application. The photophysical and fluorescence quenching studies were carried in water. It can be concluded out of all these complexes, complex 2-ClGa+F127 showed better properties hence it can be effective in possible application for PDT.

Acknowledgements. This work was supported by the Department of Science and Technology (DST)/Nanotechnology (NIC) and National Research Foundation (NRF) of South Africa through DST/NRF South African Research Chairs Initiative for Professor of Medicinal Chemistry and Nanotechnology (UID 62620) and Rhodes University.

\section{References}

1. Vilsinski B.H., Gerola A.P., Enumo J.A., da Silva Souza Campanholi K., de Souza Pereira P.C., Braga G., Hiok N., Kimura E., Tessaro A.L., Caetano W. Photochem. Photobiol. 2015, 91, 518-525.

2. Sutton D., Nasongkla N., Blanco E., Gao J. Pharm. Res. 2007, 24, 1029-1046.

3. Kedar U., Phutane P., Shidhaye S., Kadam V. Nanomedicine: NBM 2010, 6, 714-729.

4. Sobczynski J., Kristensen S., Ber S. Photochem. Photobiol. Sci. 2014, 13, 8-22.

5. Alakhov V., Klinski E., Li S., Pietrzynski G., Venne A., Batrakova E.V., Bronitch T., Kabanov A.V. Colloids Surf, B: Biointerfaces 1999, 16, 113-34
6. Zhang W., Shi Y., Chen Y., Ye J., Sha X., Fang X. Biomaterials 2011, 32, 2894-2906.

7. Sezgin Z., Yu"ksel N., Baykara T. Eur. J. Pharm. Biopharm. 2006, 64, 261-268.

8. Kano K., Fukuda K., Wakami H., Nishiyabu R., Pasternack R.F. J. Am. Chem. Soc. 2000, 122, 7494-7502.

9. Whitesides G.M., Mathias J.P., Seto C.T. Science 1991, 254, 1312-1319.

10. Tozoni J.R., Barbosa N.M., Neto C.A., Ribeiro W.M., Pazin A., Ito S., Borissevitch I.E., Marletta A. Polymer 2016, 102, 136-142.

11. Sigge U., Bindig U., Endisch C., Komatsu T., Tsuchida E., Voigt J., Fuhrhop J.H. Ber. Bunsen-Ges. Phys. Chem. 2010, 100, 2070-2075.

12. Kwon G.S., Kataoka K. Adv. Drug Delivery Rev. 1995, 16(2-3), 295-309.

13. Managa M., Britton J., Prinsloo E., Nyokong T. J. Coord Chem. 2016, 69, 3491-3506.

14. Bakar M.B., Oelgemoller M., Senge M.O. Tetrahedron 2009, 65, 7064-7078.

15. Managa M., Mkhize S., Britton J., Prinsloo E., Nyokong T. J. Coord. Chem. 2016, 69, 3035-3042.

16. Tshangana C., Nyokong T. J. Fluoresc. 2015, 25, 199-210.

17. Fery-Forgues S., Lavabre D. J. Chem. Educ. 1999, 76, $1260-1264$.

18. Brookfield R.L., Ellul H., Harriman A., Porter G. J. Chem. Soc., Faraday Trans. 1986, 82, 219-233.

19. Kuznetsova N.A., Gretsova N.S., Yuzhakova O.A., Negrimovskii V.M., Kaliya O.L., Luk'yanets E.A. Russ. J. Gen. Chem. 2001, 71, 36-44.

20. Tanielian C., Wolff C., Esch M. J. Phys. Chem. 1996, 100, 6555-60.

21. Managa M., Ngoy B.P, Mafukidze D., Britton J., Nyokong T. J. Photochem. Photobiol. A: Chemistry 2017, 348, 179-187.

22. Eloy J.O., Marchetti J.M. Powder Technol. 2014, 253, 98-106.

23. Ye X., Zhang J., Chen H., Wang X., Huang F. Appl. Mater. Interfaces 2014, 6, 5113-5121.

24. Takayama S.J., Ukpabi G., Murphy M.E.P., Mauk A.G. PNAS 2011, 108, 13071-13076.

25. Togashi D.M., Costa S.M.B., Sobral A.J.F.N., Gonsalves A.M.d'A.R. J. Phys. Chem. B 2004, 108, 11344-11356.

26. Vilsinski B.H., Aparicio J.L., de Souza Pereira P.C., Fávaro S.L., Campanholi K.S.S., Gerola A.P., Tessaro A.L., Hioka N., Caetano W. Quim. Nova 2014, 37(10), 1650-1656.

27. Uttamlal M., Holmes-Smith A.S. Chem. Phys. Lett. 2008, 454, 223-28.

28. Wenceslau A.C., Ferreira G.L.Q.C., Hioka N., Caetano W. J. Porphyrins Phthalocyanines 2015, 19, 1168-1176.

29. Basak R., Bandyopadhyay R. Langmuir 2013, 29, 4350-4356.

30. Kotov S.L., Timofeev V.A., Belkov G.V., Aksenov N.A., Soloviev A.B. Micron 2012, 43, 445-449.

31. Lakowicz J.R. Principles of Fluorescence Spectroscopy (3rd ed.). New York: Springer Science Business Media, LCC, 2006.

32. Jameson D.M. Introduction to Fluorescence. United State: CRC Press, Taylor \& Francis Group, 2014.

33. Gu Z., Lei W., Shi W., Hao Q, Si W., Xia X., Wang F. Spectrochim. Acta, Part A 2014, 132, 316-68.

34. Pellosi D.S., Estevão B.M., Freitas C.F., Tsubone T.M., Caetano W., Hioka N. Dyes Pigm. 2013, 99, 705-712. 